antibodies in SPA and PA, to recommend systematically the eviction of etanercept in subjects with a moderate risk of developing anterior uveitis.

Disclosure of Interest: None declared

DOI: 10.1136/annrheumdis-2018-eular.3342

\section{SAT0283 $\quad$ SECUKINUMAB 150 MG PROVIDES SUSTAINED IMPROVEMENTS IN THE SIGNS AND SYMPTOMS OF ACTIVE ANKYLOSING SPONDYLITIS WITH HIGH RETENTION RATE: 4-YEAR RESULTS FROM THE PHASE III TRIAL, MEASURE 2}

H. Marzo-Ortega ${ }^{1}$, J. Sieper ${ }^{2}$, A. Kivitz ${ }^{3}$, R. Blanco ${ }^{4}$, M. Cohen ${ }^{5}$, E.M. Delicha ${ }^{6}$, S. Rohrer ${ }^{6}, \mathrm{H}$. Richards ${ }^{6}$ on behalf of MEASURE 2 Study Group. ${ }^{1} N I H R$ LMBRU, LTHT and LIRMM, UoL, Leeds, UK; ${ }^{2}$ University Clinic Benjamin Franklin, Berlin, Germany; ${ }^{3}$ Altoona Center for Clinical Research, Duncansville, USA; ${ }^{4}$ Hospital Universitario Marqués de Valdecilla, Santander, Spain; ${ }^{5}$ McGill University, Montreal, Canada; ${ }^{6}$ Novartis Pharma AG, Basel, Switzerland

Background: Secukinumab, a fully human monoclonal antibody that neutralises IL-17A, has shown significant and sustained improvement in the signs and symptoms of active ankylosing spondylitis (AS) through 3 years in the MEASURE 2 study (NCT01649375). ${ }^{1}$

Objectives: To report the longer-term (4 year) efficacy and safety of subcutaneous (s.c.) secukinumab $150 \mathrm{mg}$ in the MEASURE 2 study.

Methods: AS patients ( $p t s ; n=219$ ) were randomised to receive s.c. secukinumab $150 \mathrm{mg}, 75 \mathrm{mg}$ or placebo at baseline, Weeks (Wks) 1, 2 and 3 and every 4 weeks from Wk 4. At Wk 16, placebo-treated pts were re-randomised to receive secukinumab 150/75 mg. Efficacy results are reported for pts initially randomised to secukinumab $150 \mathrm{mg}$ and those who switched from placebo to secukinumab $150 \mathrm{mg}$ at Wk 16 . Safety analyses included all pts who received $\geq 1$ dose of secukinumab. Results are reported as observed.

Results: The retention rate from Wk 16 to 208 was 85\% (85/100) for secukinumab $150 \mathrm{mg}$. Sustained improvements were observed with secukinumab $150 \mathrm{mg}$ across all endpoints through 4 years (Table). These improvements were maintained regardless of prior exposure to anti-TNF therapy; greater responses were demonstrated in anti-TNF-naïve pts. Over the entire study period, the mean exposure $( \pm S D)$ to secukinumab was $1189.3 \pm 452.9$ days. Exposure-adjusted incidence rates (per 100 pt-years) with any secukinumab dose for selected adverse events were: serious infections/infestations (1.5), Candida infections (1.2), Crohn's disease (0.6), major adverse cardiovascular events $(0.6)$, uveitis $(0.6)$, and malignant/unspecified tumours (0.4).

Abstract SAT0283 - Table 1. Clinical improvements with secukinumab $150 \mathrm{mg}$ at Weeks 52 and 208

\begin{tabular}{lcccc}
\hline Variable & Week & \multicolumn{3}{c}{ Secukinumab 150 mg $^{\text {a }}$} \\
\cline { 3 - 5 } & & Total & $\begin{array}{c}\text { Anti-TNF- } \\
\text { naïve }\end{array}$ & $\begin{array}{c}\text { Anti-TNF- } \\
\text { IR }\end{array}$ \\
\hline ASAS20,\% responders (n) & 52 & $74.2(93)$ & $80.0(60)$ & $63.6(33)$ \\
& 208 & $73.3(86)$ & $74.6(59)$ & $70.4(27)$ \\
ASAS40,\% responders (n) & 52 & $57.0(93)$ & $63.3(60)$ & $45.5(33)$ \\
& 208 & $60.5(86)$ & $62.7(59)$ & $55.6(27)$ \\
BASDAI, mean change $\pm S D(n)$ & 52 & $-3.2 \pm 2.3$ & $-3.3 \pm 2.3(60)$ & $-3.0 \pm 2.1$ \\
& & $(93)$ & & $(33)$ \\
& 208 & $-3.2 \pm 2.3$ & $-3.5 \pm 2.4(59)$ & $-2.7 \pm 2.0$ \\
SF-36 PCS, mean change $\pm S D(n)$ & 52 & $7.6 \pm 7.7(94)$ & $8.0 \pm 7.5(61)$ & $6.9 \pm 8.1(33)$ \\
& 208 & $8.3 \pm 8.3(85)$ & $9.4 \pm 8.5(58)$ & $6.2 \pm 7.8(27)$ \\
ASAS partial remission,\% & 52 & $24.7(93)$ & $28.3(60)$ & $18.2(33)$ \\
responders (n) & 208 & $27.9(86)$ & $32.2(59)$ & $18.5(27)$ \\
\hline
\end{tabular}

ancludes placebo switchers. Data are reported as observed.

ASAS; Assessment in SpondyloArthritis International Society; BASDAI, Bath Ankylosing Spondylitis Disease Activity Index; IR, inadequate response; SD, standard deviation; SF-36 PCS, Short Form ${ }^{36}$ Health Survey Physical Component Summary; TNF, tumour necrosis factor

Conclusions: Secukinumab $150 \mathrm{mg}$ provided sustained improvement in the signs, symptoms and physical function in pts with AS through 4 years of treatment with $85 \%$ retention rate. The safety profile of secukinumab remained favourable and was consistent with previous reports. ${ }^{1-3}$

\section{REFERENCES:}

[1] Marzo-Ortega, et al. RMD Open 2017;3:e000592.

[2] Marzo-Ortega, et al. Ann Rheum Dis 2016;75:812-3.

[3] Baraliakos, et al. Clin Exp Rheumatol 2017.
Disclosure of Interest: H. Marzo-Ortega Grant/research support from: Janssen, Celgene, Speakers bureau: Janssen, Pfizer, AbbVie, Celgene, Novartis, UCB, J. Sieper Grant/research support from: AbbVie, Pfizer, Merck, Consultant for: for AbbVie, Pfizer, Merck, UCB, Novartis, Speakers bureau: AbbVie, Pfizer, Merck, UCB, A. Kivitz Grant/research support from: Altoona Centre for Clinical Research, Consultant for: Vertex, AbbVie, Amgen, Celgene, Horizon, Genetech, Janssen, Merck, Novartis, Pfizer, UCB, Genzyme, Sanofi, Regeneron, SUN Pharma Advanced Research, Boehringer Ingeleheim, R. Blanco Grant/research support from: Abbvie, MSD, Roche, Consultant for: AbbVie, Pfizer, Roche, Bristol-Myers, Janssen, Lilly, MSD, Speakers bureau: AbbVie, Pfizer, Roche, Bristol-Myers Janssen, Lilly, MSD, M. Cohen Consultant for: Abbvie, Amgen, BMS, Celgene, Janssen, Lilly, Merck, Novartis, Paladin, Pfizer, Roche, Sanofi, UCB, E. M. Delicha Employee of: Novartis, S. Rohrer Employee of: Novartis, H. Richards Employee of: Novartis

DOI: 10.1136/annrheumdis-2018-eular.3703

\section{SAT0284 AN ADD-ON TRAINING PROGRAM INVOLVING BREATHING EXERCISES, COLD EXPOSURE, AND MEDITATION ATTENUATES INFLAMMATION AND DISEASE ACTIVITY IN AXIAL SPONDYLOARTHRITIS}

G.A. Buijze ${ }^{1}$, H.M.Y. De Jong ${ }^{2}$, M. Kox ${ }^{3}$, D. van Schaardenburg ${ }^{2}$, R.M. van Vugt ${ }^{4}$, C. Popa ${ }^{5}$, P. Picckers ${ }^{3}$, D.L. Baeten ${ }^{2} .{ }^{1}$ Orthopaedic Surgery, ${ }^{2}$ Clinical immunology and rheumatology, Academic Medical Center, Amsterdam; ${ }^{3}$ Intensive Care Medicin, Radboud University Medical Centre, Nijmegen; ${ }^{4}$ Rheumatology, VU medical center, Amsterdam; ${ }^{5}$ Rheumatology, Sint Maartenskliniek, Nijmegen, Netherlands

Background: A training program involving breathing exercises, cold exposure, and meditation (further referred to as: 'add-on training program') was shown to exert immunomodulating properties in healthy individuals undergoing experimental endotoxemia.

Objectives: Assessment of safety and anti-inflammatory effects of the add-on training program in patients with axial spondyloarthritis $(\mathrm{axSpA})$.

Primary objectives: safety (24 weeks) and change in serum CRP levels (week 8 ) Secondary objectives: changes in erythrocyte sedimentation rate (ESR), serum calprotectin levels, disease activity as measured by the ASDAS-CRP and Bath Ankylosing Spondylitis Disease Activity Index (BASDAI), quality of life measures (SF-36, EQ-5D), and hospital anxiety and depression scale (HADS).

Methods: 24 patients with moderatly active axSpA (ASDAS >2.1 and $\mathrm{CRP}>5 \mathrm{mg} / \mathrm{L}$ ) were included in this trial. The intervention consisted of an 8 weeks add-on training program comprising three elements: breathing exercises (cyclic hyperventilation followed by breath retention), gradual cold exposure (immersions in ice cold water), and meditation (third eye meditation). An open-label randomised one-way crossover design was used to rule out regression to the mean by comparing an intervention group with a control group.

\section{CRP}



Results: There was no significant difference in adverse events between groups, with one serious adverse event (hypertensive crisis) occurring 8 weeks after end of the intervention and judged 'unrelated'. The study met its primary efficacy endpoint, with a significant decline in serum CRP at week 8 in the intervention group 
(median [interquartile range] from $10.2[6.5-17.1]$ to 6.0 [3.9-15.6] $\mathrm{mg} / \mathrm{L} ; \mathrm{p}=0.02$ ), but not in the control group (from $8.7[5.2-17.2]$ to $13.2[7.9-20.1] \mathrm{mg} / \mathrm{L} ; \mathrm{p}=0.70$ ). A similar trend was seen for serum calprotectin $(p=0.065$ in intervention versus $\mathrm{p}=0.31$ in control), but not for ESR. In addition, ASDAS-CRP $(\mathrm{p}=0.02)$, BASDAI $(p=0.04)$, SF-36 physical component score $(p=0.01), E Q-5 D(p=0.049)$, and EQ$5 D$ VAS $(p=0.02)$ decreased significantly in the intervention group, but not the control group.

Conclusions: This proof-of-concept study in axSpA revealed a significant decrease in serum CRP levels upon add-on training program, in the absence of safety signals. Together with the significant improvement in disease activity and quality of life, these findings warrant full-scale randomised controlled trials of this novel therapeutic approach in patients with axSpA and other inflammatory conditions.

Disclosure of Interest: None declared

DOI: 10.1136/annrheumdis-2018-eular.1820

\section{SAT0285 EFFICACY OF EARLY VERSUS DELAYED INITIATION OF ANTI-TNF-ALPHA TREATMENT IN AXIAL SPONDYLOARTHRITIS. DATA FROM THE CZECH REGISTRY ATTRA}

H. Mann ${ }^{1}$, K. Bubová ${ }^{1}$, J. Závada ${ }^{1}$, Š. Forejtová ${ }^{1}$, Z. Křístková ${ }^{2}$, L. Szczuková ${ }^{2}$, P. Horák ${ }^{3}$, J. Vencovský ${ }^{1}$, K. Pavelka ${ }^{1}$ on behalf of ATTRA registry. ${ }^{1}$ Institute of Rheumatology, Prague 2; ${ }^{2}$ Institute of Biostatistics and Analyses, Faculty of Medicine, Masaryk University, Brno; ${ }^{3}$ III Department of internal Medicine, Faculty of Medicine and Dentistry, Palacký University Olomouc, Olomouc, Czech Republic

Background: Anti-TNF- $\alpha$ agents are the mainstay of pharmacotherapy for patients with axial spondyloarthritis $(\mathrm{AxSpA})$ who failed treatment with NSAIDs. A little is known about the influence of early versus delayed treatment initiation on their clinical efficacy.

Objectives: To compare change of disease activity in AxSpA patients on antiTNF- $\alpha$ therapy based on symptom duration prior to treatment initiation.

Methods: Baseline demographic data and efficacy parameters of patients starting their first anti-TNF- $\alpha$ treatment $\leq 10$ years (EARLY) or $>10$ years (DEALYED) after first symptoms of $\mathrm{AxSpA}$ from the Czech national registry ATTRA were compared. Mean $\pm S D$ and absolute/relative frequencies were used to describe continuous and categorical variables, respectively. P-value of Fisher's exact test and Mann-Whitney test is given when assessing difference between groups in categorical and continuous variables. ATTRA is a centralised prospective computerised registry of patients receiving bDMARD therapy for rheumatic diseases collecting data on efficacy, safety and quality of life of all patients treated in the Czech Republic. Anti-TNF- $\alpha$ therapy was indicated for patients with AxSpA who have failed treatment with NSAIDs with CRP $\geq 1 \mathrm{mg} / \mathrm{dl}$ and BASDAI score $\geq 4$.

Results: Data from 1290 axSpA patients were available for analysis. 618 patients started treatment $\leq 10$ years (EARLY) and $672>10$ years (DELAYED) after the onset of $\mathrm{AxSpA}$ symptoms. There was no significant difference in gender distribution (71.4 vs $72.5 \%$ males; $p=0.67$ ) or age at $A x S p A$ diagnosis $(33.3 \pm 10.4$ vs 33.5 $\pm 10.4 ; p=0.68)$ between the two groups. At the time of anti-TNF- $\alpha$ initiation EARLY patients were significantly younger $(36.4 \pm 10.6$ vs $44.0 \pm 11.2$ years; $\mathrm{p}<0.001)$ with shorter symptom duration $(5.5 \pm 2.7$ vs $18.9 \pm 8.1 ; p<0.001)$, but disease activity assessed by BASDAI $(6.3 \pm 1.8$ vs $6.3 \pm 1.6 ; p=0.81)$ and serum CRP levels $(2.6 \pm 2.5$ vs $2.4 \pm 2.0 \mathrm{mg} / \mathrm{dL} ; \mathrm{p}=0.34$ ) were comparable in both groups. Mean change of BASDAI scores from baseline during anti-TNF- $\alpha$ therapy was significantly greater in the EARLY group at all time-points $(3.7 \pm 2.5$ vs $3.4 \pm 2.2$ at month $3,4.2 \pm 2.5$ vs $3.8 \pm 2.3$ at month $6,4.4 \pm 2.5$ vs $4.0 \pm 2.3$ at month 12 and 4.4 \pm 2.5 vs $4.0 \pm 2.4$ at month $24 ; p<0,05$ for all) suggesting better treatment response. The difference in survival on therapy between the two groups was not statistically significant.

Conclusions: AxSpA patients starting anti-TNF- $\alpha$ therapy more than 10 years after onset of symptoms have significantly worse response to treatment compared to patients with earlier treatment initiation.

Acknowledgements: This study was supported by the project of MHCR for conceptual development of research organisation 00023728

Disclosure of Interest: None declared

DOI: 10.1136/annrheumdis-2018-eular.3610

\section{SAT0286 \\ RETENTION RATE AND SAFETY DATA OF BIOSIMILAR CT-P13 IN ANKYLOSING SPONDYLITIS PATIENTS: DATA FROM THE KOREAN COLLEGE OF RHEUMATOLOGY BIOLOGICS REGISTRY}

H.-A. Kim ${ }^{1}$, E.-Y. Lee ${ }^{2}$, S.-K. Lee ${ }^{3}$, Y.-B. Park ${ }^{4}$, K. Shin ${ }^{3} .{ }^{1}$ Department of Rheumatology, ${ }^{2}$ Department of Medical Informatics, Ajou University School of Medicine, Suwon; ${ }^{3}$ Department of Internal Medicine (Division of Rheumatology), Seoul Metropolitan Government-Seoul National University Hospital Boramae Medical Center, ${ }^{4}$ Department of Internal Medicine (Division of Rheumatology), Yonsei University College of Medicine, Severance Hospital, Seoul, Korea, Republic Of

Background: CT-P13 is a biosimilar prescribed in a number of countries for indications approved for the reference infliximab (RINF), including ankylosing spondylitis (AS), rheumatoid arthritis, and inflammatory bowel diseases. Clinical data of CT-P13 have been analysed in previous clinical trials, demonstrating equivalence of efficacy and pharmacokinetic profile to RINF. However, there are few studies showing long-term data of its drug survival or safety.

Objectives: To investigate the drug retention rate and safety data of biosimilar CT-P13 in Korean AS patients.

Methods: Subjects were AS patients enrolled in the Korean College of Rheumatology biologics registry (KOBIO). Data from patients who received RINF and CTP13 were included in the analysis ${ }^{\text {Dec } 2012} \sim$. Dec 2017 Discontinuation was defined as switching or stopping the biologic agent. Kaplan-Meier curve and Cox proportional hazard model were used for further analysis. Reason for RINF or CT-P13 discontinuation was also assessed.

Results: Data from 399 AS patients (CT-P13; 256, RINF; 143) were analysed. The mean age of patients was 39.0 in the CT-P13 group, and 73\% were males. The mean disease duration was 4.1 years. Eighty percent of patients were firsttime biologic users. Discontinuation of CT-P13 occurred in $30.9 \%$ (switching in $17.6 \%$ ) of patients during follow-up. The drug retention rate of first-line users of CT-P13 was marginally higher compared with second or more $(\geq 2)$-line users of CT-P13, first-line users of RINF, and $\geq 2$ line users of CT-P13 in Korean AS patients $(p=0.0518)$. The reason of discontinuation was inefficacy $(42.7 \%)$, adverse events $(20.2 \%)$, clinical improvement $(7.9 \%)$, and others $(18.0 \%)$ in the CT-P13 group. The incidence of adverse events of CT-P13, including infusion reaction $(n=10)$, mycobacterial infection $(n=2)$, and skin eruption $(n=1)$ was comparable to that of RINF.

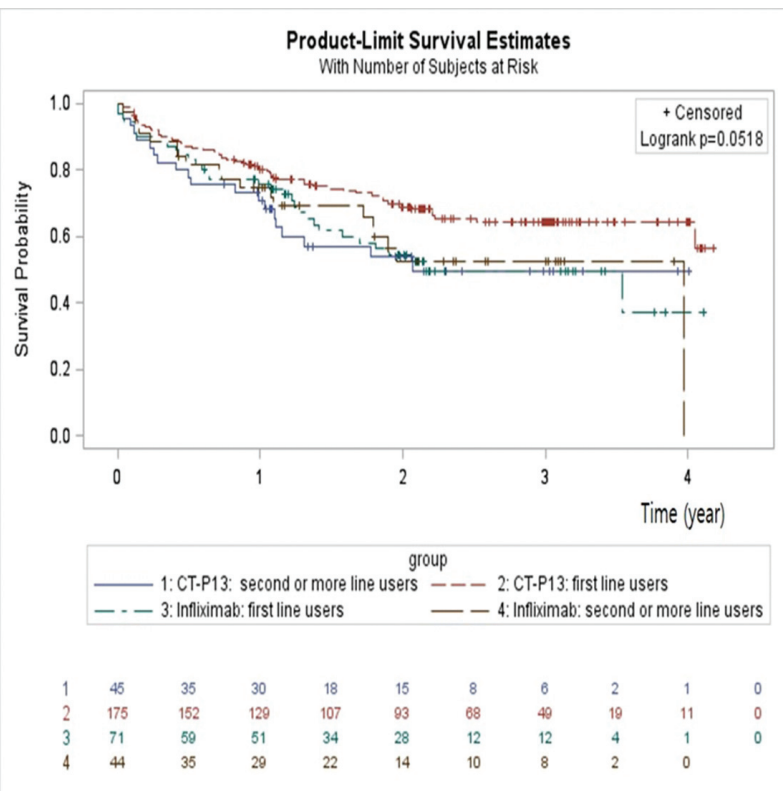

Conclusions: Our study demonstrates that the drug retention rate of CT-P13 especially in first-line users was relatively higher than that of RINF, [H1] and CT$\mathrm{P} 13$ showed a reasonable long-term safety profile in Korean AS patients.

Disclosure of Interest: None declared

DOI: 10.1136/annrheumdis-2018-eular.6182 